\title{
The prostate cancer drug enzalutamide shortens anogenital distance in male rat offspring by blocking the androgen receptor
}

Camilla Lindgren Schwartz

Danmarks Tekniske Universitet

Terje Svingen

Danmarks Tekniske Universitet

Camilla Taxvig

Danmarks Tekniske Universitet

Sofie Christiansen

Danmarks Tekniske Universitet

Mikael Pedersen

Danmarks Tekniske Universitet

Henrik Lauritz Frandsen

Danmarks Tekniske Universitet

Annemette Fribo Gøttsche

Danmarks Tekniske Universitet

Katrine Ankjær Frederiksen

Danmarks Tekniske Universitet

Hanna Katarina Lilith Johansson

Danmarks Tekniske Universitet

Anne Marie Vinggaard ( $\sim$ annv@food.dtu.dk)

Danmarks Tekniske Universitet https://orcid.org/0000-0002-6822-3572

Research article

Keywords: Enzalutamide, antiandrogen, androgen receptor, testosterone, anogenital distance

Posted Date: November 27th, 2019

DOl: https://doi.org/10.21203/rs.2.17827/v1

License: (c) (1) This work is licensed under a Creative Commons Attribution 4.0 International License.

Read Full License 


\section{Abstract}

Background: Enzalutamide is a non-steroidal anti-androgen drug used to treat prostate cancer. It is a potent androgen receptor (AR) antagonist, with an in vitro Lowest Observed Effect Concentration (LOEC) of $0.05 \mu \mathrm{M}$. In this study, we wanted to assess its utility as a model compound for future mechanistic studies aimed at delineating mechanism-of-action of anti-androgenic effects in the developing fetus.

Methods: Enzalutamide in vitro activity was tested using an Androgen receptor reporter assay (AREcoScreenTM) and a steroidogenesis assay (H295R assay). For in vivo characterization, pregnant Sprague-Dawley rats were exposed to $10 \mathrm{mg} / \mathrm{kg}$ bw/day enzalutamide from gestational day 7-21. At gestational day 21, enzalutamide exposure concentrations were measured both in amniotic fluids and fetal plasma, alongside Anogenital distance (AGD). Fetal testes were collected and for testosterone measurements and gene expression profiling.

Results: Enzalutamide was a strong AR antagonist in vitro and we also observed disrupted androgen synthesis in the H295R steroidogenic assay with a LOEC of $3.1 \mu \mathrm{M}$. In utero exposure resulted in about $20 \%$ shorter anogenital distance (AGD) in male fetuses., as well as signs of dysregulated expression of the steroidogenic genes Star, Cyp11a1 and Cyp17a1 in the fetal testes at gestational day 21. Intratesticular testosterone levels were unaffected.

Conclusions: Based on these observations, together with in vitro LOECs and the fetal plasma levels of enzalutamide, we propose that the effect on male AGD was caused by AR antagonism rather than suppressed androgen synthesis. Due to the characteristic mechanism of action of enzalutamide, we suggest to use it as a new model compound in research on anti-androgenic environmental chemicals.

\section{Background}

Androgen signaling is critical for male reproductive tract development and general masculinization of the fetus (1). Exposure to anti-androgens during fetal life can therefore lead to a broad range of male reproductive disorders such as hypospadias and cryptorchidism at birth $(2,3)$ or fertility issues in adulthood $(4,5)$. Anti-androgens can also cause general feminization of the male fetus, which can lead to a short male anogenital distance (AGD); a marker for disrupted fetal androgen action associated with male reproductive disorders $(6-8)$.

Because of the strong link between fetal androgen insufficiency, male AGD, and male reproductive health disorders, both in humans and animals, AGD measurements are routinely performed in tests for developmental and reproductive toxicity in chemical risk assessment (9-12). However, it remains unclear to what extent AGD can be used as a reliable biomarker for chemicals with different anti-androgenic modes of action (8). To gain the necessary knowledge to characterize cause-effect relationships and thus better define the utility of a biomarker such as AGD, performing studies on various model compounds with known mechanism of action is of particular interest. With respect to androgen-sensitive endpoints, 
selective drugs such as enzalutamide or the 5a-reductase inhibitor finasteride are attractive model compounds due to their known, yet different, modes of action.

Enzalutamide is a second generation prostate cancer drug used to treat metastatic Castration-Resistant Prostate Cancer (mCRPC) for which the first generation drugs are not efficient (13-15). It is a nonsteroidal anti-androgen that acts as an antagonist of the androgen receptor (AR) - the biological target of androgens such as testosterone and dihydrotestosterone - thereby preventing the effects of these hormones in the prostate gland (14). While first generation drugs such as bicalutamide target AR transcriptional activity by interfering with recruitment of co-activators to the transcriptional complex (16, 17), enzalutamide targets three key stages of AR signaling: blocking androgen binding, inhibiting translocation of activated AR and inhibiting binding of activated AR to the DNA (14). Thus, enzalutamide is a potent, specific inhibitor of androgen signaling.

We recently completed a study using the $5 \mathrm{a}$-reductase inhibitor finasteride as a model compound in an effort to tease out some of the underlying molecular mechanisms driving effects on male AGD (18). Based on in vitro data we found that enzalutamide apart from blocking the AR also inhibited androgen synthesis in vitro. To follow up on this, we tested enzalutamide in an in utero exposure study based on its known antiandrogenic effect in order to investigate, if the compound affected AGD and, if so, which mechanism was underlying the effect. We found that the AGD of the late gestation male fetuses were significantly shorter and that gene expression levels of steroidogenic enzymes in the fetal testis at GD21 were affected, albeit without significantly affecting the intra-testicular testosterone levels. Thus, we conclude that enzalutamide causes it AGD effect by antagonizing the AR.

\section{Methods}

\section{Test compound}

The test compound used in this study was Enzalutamide (purity 98\%, CAS No.: 915087-33-1) purchased from Advanced Chemblocks Inc. (G-7963). Corn oil was purchased from Sigma-Aldrich (Copenhagen, Denmark) and used as control compound and vehicle (product number: C8267-2.5L).

\section{AR-EcoScreen ${ }^{\mathrm{TM}}$ assay}

The antagonistic effects of enzalutamide on AR were investigated using the Androgen Receptor Stably Transfected Transcriptional Activation Assay (AR STTA) described in OECD test guideline no. 458 (19). Experiments were run with three technical replicates and repeated thrice, with the mean value of technical replicates representing one biological replicate. AR-EcoScreen ${ }^{\text {TM }}$ cells (JCRB1328, Japanese Collection of Research Bioresources) were grown in CellBIND $\circledast$ Surface cell culture flasks (Corning ${ }^{\circledR}$ Inc., Corning, New York, USA) in growth medium consisting of Gibco ${ }^{\circledR}$ DMEM/F-12 Nutrient Mixture with L-glutamine and HEPES and without phenol red supplemented with 5\% FBS, $1 \%$ Penicillin-Streptomycin, $200 \mu \mathrm{g} / \mathrm{ml}$ Zeocin $^{\text {TM }}$ Selection Reagent, and $100 \mu \mathrm{g} / \mathrm{ml}$ Hygromycin B (all reagents from Invitrogen ${ }^{\mathrm{TM}}$, Life Technologies $^{\mathrm{TM}}$, Carlsbad, California, USA). The cells were incubated at $37^{\circ} \mathrm{C}$ with a humidified 
atmosphere of $5 \% \mathrm{CO}_{2}$ and $95 \%$ air. Only cells of passage $3-15$ were used for experiments. One day prior to the experiment cells were plated in white 96-well plates (Corning ${ }^{\circledR}$ Inc., Corning, New York, USA) at a density of 9,000 cells/well in assay medium consisting of Gibco ${ }^{\circledR}$ DMEM/F-12 Nutrient Mixture medium, $1 \%$ Penicillin-Streptomycin, with 5\% dextran-coated charcoal-treated fetal bovine serum (DCC-FBS) (all reagents from Invitrogen ${ }^{T M}$, Life Technologies ${ }^{T M}$, Carlsbad, California, USA). The following day the medium was changed to assay medium containing various concentrations of enzalutamide or the control compounds R1881 (known AR agonist, Perkin Elmer) or hydroxyflutamide (known AR antagonist, CAS No. 52806-53-8, Toronto Research Chemicals, Toronto, Ontario, Canada). Enzalutamide was added to the cells in 2-fold serial dilutions ranging from $0.05-12.5 \mu \mathrm{M}$. The DMSO vehicle concentrations were constant in all wells. R1881 was added at a concentration of $0.1 \mathrm{nM}$ to all wells when testing for AR antagonism. After cells had been exposed to test compounds for $\sim 20$ hours firefly luminescence was measured in a luminometer (LUMIstar ${ }^{\circledR}$ Galaxy, BMG LABTECH, Offenburg, Germany) using DualGlo®ILuciferase Reagent from the Dual-Glo® Luciferase Assay System from Promega (Madison, Wisconsin, USA). In order to distinguish a decrease in luciferase activity caused by pure antagonism from that caused by cytotoxicity, we measured Renilla luminescence using Dual-Glo® Stop \& Glo® Reagent from the Dual-Glo $\circledast$ Luciferase Assay System (Promega, Madison, Wisconsin, USA).

\section{H295R steroidogenesis assay}

The ability of enzalutamide to affect steroidogenesis was investigated using the H295R Steroidogenesis Assay described in OECD test guideline no.456 (20). The H295R human adrenocortical carcinoma cell line (CRL-2128 ${ }^{\text {TM }}$, ATCC $\circledast$, Manassas, Virginia, USA) was cultured in CellBIND ${ }^{\circledR}$ Surface cell culture flasks (Corning ${ }^{\circledR}$ Inc., Corning, New York, USA) in DMEM/F-12 growth medium with L-glutamine and HEPES and without phenol red (Invitrogen ${ }^{T M}$, Life Technologies ${ }^{T M}$, Carlsbad, California, USA) supplemented with 1\% ITS + premix media additive (Corning ${ }^{\circledR}$ Inc., Corning, New York, USA) and 2.5\% Nu-SerumTM (Corning ${ }^{\circledR}$ Inc., Corning, New York, USA). The cells were incubated at $37^{\circ} \mathrm{C}$ with a humidified atmosphere of $5 \% \mathrm{CO}_{2}$ and $95 \%$ air. Only cells of passage 4-9 were used for experiments. One day prior to the experiment cells were plated in clear 24-well plates (Corning ${ }^{\circledR}$ Inc., Corning, New York, USA) at a final density of 300,000 cells/well. Cells were incubated with enzalutamide (2-fold serial dilutions ranging from $0.05-12.5 \mu \mathrm{M}$ ) for $48 \mathrm{hrs}$ after which the supernatant was repositioned to new 24 -well plates stored at $-80^{\circ} \mathrm{C}$ until quantification of hormone levels by HPLC-MS/MS. A quality control plate with the control compounds Forskolin ( 1 and $10 \mu \mathrm{M})$ (Sigma-Aldrich, Copenhagen, Denmark) and prochloraz ( 0.3 and $3 \mu \mathrm{M})$ (Ehrenstorfer, VWR \& Bie \& Berntsen, Denmark) were included in all experiments to monitor assay performance. Three independent experiments were performed each with technical triplicates.

After removal of the supernatant, cytotoxicity was evaluated using fluorescamine (CAS no. 38183-12-9, Sigma-Aldrich ${ }^{\circledR}$, St. Louis, Missouri, USA). Cells were washed with $500 \mu \mathrm{l} /$ well pre-warmed $\left(37^{\circ} \mathrm{C}\right) \mathrm{PBS}$. $150 \mu \mathrm{l} /$ well lysis buffer were added and plates were shaked for $15 \mathrm{~min}$. Hereafter, $400 \mu \mathrm{l}$ of pre-warmed $\left(37^{\circ} \mathrm{C}\right)$ fluorescamine diluted in acetonitrile to a final concentration of $500 \mu \mathrm{g} / \mathrm{ml}$ was added to each well and placed dark in an incubator with a humidified atmosphere of 5\% CO2 and $95 \%$ air for $20 \mathrm{~min} .300 \mu \mathrm{l}$ of the supernatant was transferred to white opaque 24-well plates (PerkinElmer, Waltham, 
Massachusetts, USA) and cell viability was evaluated by measuring fluorescence using an EnSpire ${ }^{\circledR}$ Multilabel Reader (PerkinElmer, Massachusetts, USA) with excitation and emission wavelengths of $390 \mathrm{~nm}$ and $460 \mathrm{~nm}$, respectively.

\section{Hormone analysis by HPLC-MS/MS}

Steroid hormones were extracted and quantified as previously described $(21,22)$, with minor modifications. Before LC-MS/MS analysis, deuterated internal standards were added to the cell extracts and samples were centrifuged (15,000 g, $10 \mathrm{~min})$. Steroid hormones were separated, detected, and quantified using on-line-SPE LC-MS/MS. For on-line SPE an Oasis HLB column $(2.1 \times 20 \mathrm{~mm}, 15 \mu \mathrm{m})$ was used. For $17 \beta$-estradiol and estrone analysis, a Kinetex $\mathrm{C}_{18}$ column $(2.1 \times 100 \mathrm{~mm}, 2.6 \mu \mathrm{m})$ was used with an injection volume of $100 \mu \mathrm{l}$, measuring in ESI- mode using methanol, and $1 \mathrm{mM}$ ammonia in water as the mobile phases (gradient flow rate was $0.4 \mathrm{ml} / \mathrm{min}$ ). For the other hormones an Ascentis Express $\mathrm{C}_{8}$ column $(2.1 \times 100 \mathrm{~mm}, 2.7 \mu \mathrm{m})$ was used with an injection volume of $100 \mu \mathrm{l}$, measuring in ESI-/ESI + mode with acetonitrile and $0.1 \%$ formic acid in water as the mobile phases (gradient flow rate was $0.25 \mathrm{ml} / \mathrm{min}$ ). Ten hormones: testosterone, androstenedione, dehydroepiandrosterone (DHEA), corticosterone, cortisol, pregnenolone, progesterone, 17a-OH-progesterone, estradiol and estrone were quantified. The limit of quantification (LOQ) was $0.1 \mathrm{ng} / \mathrm{ml}$ for corticosterone, $1.0 \mathrm{ng} / \mathrm{ml}$ for DHEA and pregnenolone, $0.02 \mathrm{ng} / \mathrm{ml}$ for testosterone and androstenedione, $0.05 \mathrm{ng} / \mathrm{ml}$ for $17 \mathrm{a}-\mathrm{OH}$-progesterone, and $0.01 \mathrm{ng} / \mathrm{ml}$ for all the other hormones. For quantification, external calibration standards were run before and after the samples at levels of $0.1,0.2,0.5,1.0,2.0,5.0$ and $20 \mathrm{ng} / \mathrm{ml}$, with $5.0 \mathrm{ng} / \mathrm{ml}$ internal standards: (testosterone-d2, methyltestosterone-d3, progesterone-c2, and estradiol-d3). The mass spectrometer was an EVOQ Elite Triple Quadropole Instrument from Bruker (Bremen, Germany) and the UPLC system was an Ultimate 3000 system with a DGP-3600RS dual-gradient pump.

\section{Animal study}

Twelve time-mated nulliparous, young adult Sprague Dawley rats with a body weight of approximately $255 \pm 25 \mathrm{~g}$ were supplied at gestational day (GD)3 (NTac:SD, SPF, Taconic Europe, Ejby, Denmark). The day of vaginal plug detection was designated GD1. On GD4, dams were randomized and distributed into 2 groups of 6 animals with similar body weight distributions. Animals were housed in pairs until GD17 and thereafter individually. The animals were housed under standard conditions in semi-transparent polysulfone (PSU) type III cages (PSU 80-1291HOOSU Type III, Tecniplast, Buguggiate, Italy) $(15 \times 27 \times$ $43 \mathrm{~cm}$ ) with Aspen wood chip bedding (Tapvei, Gentofte, Denmark), Enviro Dri nesting material (Brogaarden, Lynge, Denmark) and Tapvei Arcade 17 (Aspen wood) shelters (Brogaarden, Lynge, Denmark). They were placed in an animal room with controlled environmental conditions: 12 hr light-dark cycles with light starting at $9 \mathrm{pm}$, temperature $22 \pm 1{ }^{\circ} \mathrm{C}$, humidity $55 \pm 5 \%, 10$ air changes per hr.

All animals were fed a standard diet with Altromin 1314 (soy- and alfalfa-free, Altromin GmbH, Lage, Germany). Acidified tap water (to prevent microbial growth) in PSU bottles (84-ACBTO702SU Tecniplast) were provided ad libitum. The PSU bottles and cages as well as the aspenwood shelters (instead of plastic) were used to eliminate any risk of migration of bisphenol A that could potentially confound the 
study results. From GD7-21, dams were weighed daily and dosed by oral gavage by qualified animal technicians with a stainless steel probe $1.2 \times 80 \mathrm{~mm}$ (Scanbur, Karlslunde, Denmark) with either vehicle control (corn oil) or enzalutamide ( $10 \mathrm{mg} / \mathrm{kg} \mathrm{bw} /$ day) at a constant volume of $2 \mathrm{ml} / \mathrm{kg} \mathrm{bw}$ per day. All animals were decapitated (guillotined) under CO2/02-anesthesia at GD21.

\section{Caesarean sections GD 21}

Dams were decapitated (guillotined) under $\mathrm{CO}_{2} / \mathrm{O}_{2}$-anesthesia at GD21 and fetuses were collected by caesarean section. The dams were exposed $1 \mathrm{~h} \pm 15 \mathrm{~min}$ before decapitation in the same order as Caesarean sections were performed to adjust for the chemical analysis of maternal blood, fetal blood and amniotic fluid. Uteri were taken out and weighed, and the number of live fetuses, resorptions, and implantations were registered. Body weights of the fetuses were recorded prior to decapitation (by a scissor). Maternal trunk blood was collected and transferred to heparin-coated vials. Trunk blood from all fetuses was collected and transferred to heparin-coated vials and pooled for each gender within each litter. Blood samples were kept on ice and centrifuged at $4000 \mathrm{rpm}, 4^{\circ} \mathrm{C}$ for $10 \mathrm{~min}$. Plasma was transferred to new tubes and stored at $-80^{\circ} \mathrm{C}$. Amniotic fluid was collected from all fetuses, pooled within each litter, snap frozen in liquid nitrogen and subsequently stored at $-80^{\circ} \mathrm{C}$.

AGD was measured as the distance between the genital papilla and the anus by the same, blinded technician using a stereomicroscope with a micrometer eyepiece. The AGD index (AGDi) was calculated by dividing AGD by the cube root of the body weight. Fetal testes were isolated by dissection under a stereomicroscope and placed in liquid nitrogen (for steroid hormone analysis) or RNAlater (for RT-qPCR analysis) (Qiagen, Hilden, Germany) and stored at $-80^{\circ} \mathrm{C}$. The animal experiments were carried out at DTU Food (Mørkhøj, Denmark) with ethical approval from the Danish Animal Experiments Inspectorate (license number 2015-15-0201-00553) and by the in-house Animal Welfare committee. All methods in this study were performed in accordance with relevant guidelines and regulations.

\section{Enzalutamide concentrations in vivo}

Acetonitrile, formic acid and 25\% ammonium hydroxide, all of LC-MS grade, were obtained from Sigma Aldrich, Schneldorf, Germany. Evolute ABN express columns, $30 \mathrm{mg}$, were purchased from Biotage, Sweden. Water was purified on a Milli Q system, Millipore Corporation, US. First, $50 \mu \mathrm{l}$ of plasma or amniotic fluid was transferred to an Eppendorf tube and $150 \mu \mathrm{l}$ ice cold acetonitrile was added. The samples were centrifuged at $10000 \times \mathrm{g}, 4^{\circ} \mathrm{C}$ for 10 minutes (Ole Dich Instrument makers, Denmark) and the supernatants were passed through an Evolute express ABN column. $20 \mu$ l eluate was transferred to an HPLC vial and $80 \mu \mathrm{l} 50 \%$ acetonitrile was added prior to analysis by Liquid Chromatography - Mass Spectrometry (LC-MS).

LC was performed on a Dionex Ultimate 3000 RS (Thermo Scientific, CA) with a Poroshell SB C-18 (100x $2.1 \mathrm{~mm}, 2.7 \mu \mathrm{m}$ particle size) column held at $30^{\circ} \mathrm{C}$ (Agilent technologies, Walbron, Germany). The solvent system consisted of $A: 2.5 \mathrm{mM}$ ammonium hydroxide $+0.1 \%$ formic acid in water and $\mathrm{B}$ : acetonitrile. Solvent programming were: $2 \%$ B from 0 to 1 min followed by a linear gradient to $95 \%$ B to $14 \mathrm{~min}$, isocratic $95 \%$ B from 14 to 16 min followed by reversal to initial conditions to $16.1 \mathrm{~min}$ and re- 
equilibration of the column to $20 \mathrm{~min}$. The flow rate was $0.3 \mathrm{ml} / \mathrm{min}$ from 0 to $1 \mathrm{~min}$ followed by a linear gradient to $0.4 \mathrm{ml} / \mathrm{min}$ to $14 \mathrm{~min}$, which was held to $16 \mathrm{~min}$ followed by reversal to initial conditions.

The LC system was connected to a Bruker Daltonics, maXis qTOF mass spectrometer equipped with an electrospray ion source operated in positive ion mode (Bruker Daltonics, Bremen, Germany). The ion source settings were: nebulizer pressure 2 bars, drying gas flow $8 \mathrm{l} / \mathrm{min}$, dry gas temperature $200^{\circ} \mathrm{C}$, capillary voltage $2500 \mathrm{~V}$. The scan range was from 80 to $1000 \mathrm{~m} / \mathrm{z}$ with an acquisition rate of $2 \mathrm{~Hz}$. Sodium formate dissolved in 50\% 2-propanol was introduced in the ion source in a 0.2-0.4 min time segment and used for internal calibration of the data files. Hexakisperflouroetoxyphophazene was used as lock mass calibrant. Matrix matched standard samples were prepared in blank plasma at 6 different levels in the concentration range of: 3 to $10,000 \mathrm{nM}$. Standards and blanks were analyzed in the beginning of a sequence and after each set of 20 samples. Data files were processed using QuantAnalysis (Bruker Daltonics, Bremen, Germany). Extracted ion chromatograms of m/z $465.1003 \pm$ $0.002 \mathrm{Da}$ were constructed and integrated. Plasma concentrations were calculated based on linear calibrations curves constructed using $1 / x$ weighing.

\section{Testosterone measurements}

One testicle was transferred to a beetBeater tube (Fischer Scientific, Waltham, MA, USA) and $1 \mathrm{~mL}$ of $80 \%$ acetonitrile (with internal standards, $1 \mathrm{ng} / \mathrm{ml}$ testosterone- $\mathrm{d} 2$ (Rikilt, Wageningen, Netherlands) was added. The sample was homogenised for $1 \mathrm{~min}$ and $50 \mathrm{mg}$ of Que Z-Sep (Sigma-Aldrich, St. Louis, Missouri, USA) was added followed by whirlmix for $1 \mathrm{~min}$. The sample was centrifuged at $3000 \times \mathrm{g}, 4^{\circ} \mathrm{C}$ for $10 \mathrm{~min}$ and placed at $-18{ }^{\circ} \mathrm{C}$ for $1 \mathrm{hr}$. The sample was then centrifuged at $10000 \mathrm{x} \mathrm{g} 4^{\circ} \mathrm{C}$ for $10 \mathrm{~min}$., followed by filtration through a SPE column (Waters Corporation, Milford, MA, USA) (HLB, $30 \mathrm{mg}$ ),

conditioned with $2 \mathrm{~mL} 80 \%$ acetonitrile. The sample was evaporated to dryness $\left(50^{\circ} \mathrm{C}, \mathrm{N}_{2}\right)$ and dissolved in $500 \mu \mathrm{l} 10 \%$ acetonitrile. Testosterone was detected and quantified using on-line-SPE LC-MS/MS. For on-line SPE, an Oasis HLB column $(2.1 \times 20 \mathrm{~mm}, 15 \mu \mathrm{m})$ was used and as analytical column an Ascentis Express C8 column $(2.1 \times 100 \mathrm{~mm}, 2.7 \mu \mathrm{m})$ was used with an injection volume of $100 \mu \mathrm{l}$ in $\mathrm{ES}+$ mode with acetonitrile and $0,1 \%$ formic acid in water as the mobile phases (flow rate $0.25 \mathrm{ml} / \mathrm{min}$, gradient method).

The MS was an EVOQ Elite Triple Quadropole Instrument from Bruker (Bremen, Germany) and the UPLC system was an Ultimate 3000 system with a DGP-3600RS dual-gradient pump. For quantification, external calibration standards were run before and after the samples at levels of $0.1,0.2,0.5,1.0,2.0,5.0$ and $20 \mathrm{ng} / \mathrm{ml}$ (with $5.0 \mathrm{ng} / \mathrm{ml}$ internal standards). The limit of quantification (LOQ) for testosterone was estimated as the concentrations corresponding to six times signal-to-noise, and was $<20 \mathrm{pg} /$ testicle.

\section{Synthesis of cDNA and RT-qPCR analysis}

Protocols were essentially as previously described (23). Briefly, total RNA was extracted from GD21 testis ( $n=12$ /group) using RNeasy mini kit and on-column DNasel treatment, according to manufacturer's instructions (Qiagen, Hilden, Germany). RNA was quantified by Nanodrop spectrophotometry (Nanodrop 
Technologies, Wilmington, DE) and 500 ng total RNA used to synthesize cDNA using a random primer mix (New England Biolabs, Ipswich, MA, USA) and the Omniscript kit (Qiagen, Hilden, Germany) according to manufacturer's instructions. Quantitative RT-PCR (RT-qPCR) reactions were run in technical duplicates on the QuantStudio 7 Flex Real-Time PCR System (Applied Biosystems, Thermo Fischer Scientific) in $11 \mu$ reactions containing: $3 \mu$ l diluted (1:20) cDNA, TaqMan Fast Universal Mastermix (2X) (Life Technologies, Carlsbad, CA, USA) and TaqMan Gene Expressions Assays (Life Technologies). TaqMan assays were: Hsd3b1 Rn01774741_m1, Hsd17b1 Rn00563388_g1, Nr5a1 Rn00584298_m1, Ddx4 Rn01489814_m1, Sox9 Rn01751069_mH, Rps18 Rn01428913_gH, and Sdha Rn00590475_m1. In addition, primers and probes Cyp17a1, Cyp11a1 and Star were designed in our lab (24). The following cycling conditions were used: an initial step of $95^{\circ} \mathrm{C}$ for $20 \mathrm{sec}$ followed by 45 two-step thermal cycles of $95^{\circ} \mathrm{C}$ for $1 \mathrm{sec}$ and $60^{\circ} \mathrm{C}$ for $20 \mathrm{sec}$. The relative transcript abundance was calculated using the $2^{-\Delta C T}$ method using Rps18 and Sdha as normalizing genes.

\section{Statistics}

Data from the AR-Eco Screen and H295R assay were analyzed by one-way ANOVA followed by Dunnett's post hoc test in GraphPad Prism 5 (GraphPad Software, San Diego California, USA). Results are presented as mean \pm SEM for the three independent experiments. One measurement of DHEA in the H295R assay was lost so the DHEA data presented are from two independent experiments.

In vivo data on maternal parameters, fetal body weight, AGD and AGDi, were analyzed by one-way ANOVA followed by Dunnett's post hoc test, using SAS ${ }^{8}$ (SAS Enterprise Guide 6.1, SAS Institute, Inc., Cary, NC, USA). AGD was analyzed using fetal weight as a covariate and fetal body weights were analyzed using the number of offspring per litter as covariate. For all analyses, the litter was the statistical unit. Statistical analyses were adjusted using litter as an independent, random and nested factor. For data presentation, group mean \pm SEM was calculated from 6 litters/group based on litter means.

Analysis of enzalutamide concentrations in plasma and amniotic fluid as well as RT-qPCR data and intratesticular testosterone levels was performed with student's t-test in GraphPad Prism 8 (GraphPad Software, San Diego California, USA). In cases of non-normal distribution or non-equal variance between groups, data was log-transformed prior to analysis, while the graphs still represent the untransformed data. For data presentation, mean \pm SEM was calculated from 6 litters/group (maternal plasma, amniotic fluid and fetal plasma), 1 testicle from 6 fetuses /group (fetal intra-testicular testosterone) and 1 testicle from 12 fetuses/group (RT-qPCR).

\section{Results}

Enzalutamide acts as an AR antagonist in vitro

The AR agonistic and antagonistic potential of enzalutamide were investigated using the AR-EcoScreen ${ }^{\text {TM }}$ assay (19). Enzalutamide did not show any agonistic activity (Fig. 1A) but showed AR antagonistic activity at all concentrations $(p<0.001)$ between $0.05-12.5 \mu \mathrm{M}$ (Fig. 1B). The lowest observed effect 
concentration (LOEC) was $0.05 \mu \mathrm{M}$ while the $\mathrm{IC}_{50}$ value was $0.1 \mu \mathrm{M}$. We confirmed that the reduction in luciferase activity was not due to cytotoxicity following enzalutamide exposure (Fig. 1C).

Enzalutamide affects steroidogenesis in vitro

The H295R Steroidogenesis Assay (20) was used to test whether enzalutamide affects the synthesis of ten sex steroid hormones (Fig. 2). All steroid hormones, except for the two estrogens estrone and estradiol, were affected by enzalutamide. Pregnenolone levels were slightly increased with a LOEC of 3.1 $\mu \mathrm{M}$. However, no increase was seen at concentrations of $25 \mu \mathrm{M}$ and above. The progestagens, progesterone and $17 \mathrm{a}-\mathrm{OH}$-progesterone were decreased with LOECs of 1.8 and $6.3 \mu \mathrm{M}$, respectively. The levels of the two androgens, androstenedione and testosterone were decreased, both with LOECs of $3.1 \mu \mathrm{M}$. By contrast, the adrenal androgen and precursor of the other androgens, dehydroepiandrosterone (DHEA), was increased with a LOEC of $0.8 \mu \mathrm{M}$. The corticosteroids, corticosterone and cortisol were generally decreased with LOECs of 6.3 and $25 \mu \mathrm{M}$, respectively, although cortisol was increased at $0.8 \mu \mathrm{M}$.

Enzalutamide was present in different biological compartments and male AGD was shorter in exposed animals at GD21

Pregnant Sprague Dawley rats were exposed to $10 \mathrm{mg} / \mathrm{kg}$ bw/day enzalutamide from GD7 to GD21 and maternal as well as fetal parameters were investigated at GD21. The distribution of enzalutamide in the different biological compartments (i.e. maternal plasma, amniotic fluid and fetal plasma) was determined at GD21 by HPLC-MS/MS. In maternal plasma the concentration was $1002 \pm 145 \mathrm{nM}$, while it was $285 \pm 46 \mathrm{nM}$ in amniotic fluid, and $282 \pm 53 \mathrm{nM}$ and $122 \pm 21 \mathrm{nM}$ in the plasma of the female and male fetuses, respectively (Fig. 3). We measured maternal body weight, weight gain (GD 7-21), and uterus weight to determine if enzalutamide exposure resulted in maternal toxicity, but observed no treatment-related significant differences between the groups or any signs of maternal toxicity (Table 1). In addition, the number of fetuses as well as fetal weights of both males and females were similar between the two groups (Table 1). Attesting to the anti-androgenic potential of enzalutamide, we found that both AGD and AGDi was $19 \%$ shorter $(p<0.001)$ in exposed males compared to control males (Fig. 4, Table 1). There were no significant differences in either AGD or AGDi between exposed females and control females (Table 1).

Enzalutamide affects gene expression of steroidogenic enzymes in male fetal testis, without affecting intra-testicular testosterone levels

Based on our observations that enzalutamide affects steroidogenesis in vitro, we assessed expression levels of key genes encoding steroidogenic enzymes in the male fetal testis at GD21. There was an upregulation of Star $(p<0.001)$, Cyp11a1 $(p<0.05)$, Cyp17a1 $(p<0.05)$ and a downregulation of Nr5a1 ( $<0.05$ ) following in utero exposure to enzalutamide (Fig. 5). The expression levels of the two hydroxysteroid dehydrogenase genes, Hsd3b1 and Hsd17b1, were unchanged, as were the germ cell marker gene Ddx4 and Sertoli cell marker Sox9 (Fig. 5). Next, we measured the intra-testicular 
testosterone levels, but found no significant difference between control males and exposed males (Fig. 6). Finally, histopathological assessment of H\&E stained fetal testis sections showed no adverse alterations to testis histology (Fig. 7).

\section{Discussion}

Enzalutamide is a second generation prostate cancer drug used to treat men with mCRPC (13). In this study, we explored the use of enzalutamide as a potential model compound or for investigations of antiandrogenic actions of environmental chemicals. Our particular interest in this regard is the use of targetspecific compounds to delineate the molecular mechanisms driving the development of anogenital tissues. The purpose is to obtain better knowledge on the utility of AGD as a general biomarker for fetal anti-androgenic effects.

Enzalutamide is designed to specifically target the AR (14). In our AR reporter gene assay the $I C_{50}$ for $A R$ antagonism was calculated to be $0.05 \mu \mathrm{M}$, which is close to the $\mathrm{IC}_{50}$ of $0.03-0.05 \mu \mathrm{M}$ previously reported $(14,25)$. Our results thereby confirmed that enzalutamide acts as an AR antagonist, without having any AR agonistic activity. Because of these specific antagonistic properties, we performed an in utero exposure study in rats, with focus on effects on the male AGD.

We measured the concentration of enzalutamide in maternal plasma, amniotic fluid and fetal plasma at GD 21 in Sprague Dawley rats and found it present in all three compartments. These data clearly show that enzalutamide can transfer across the placenta, albeit the maternal concentration was about four times higher than in the fetal compartments. Notably, we also measured almost twice the concentration of enzalutamide in male plasma compared to female. It remains unclear why this difference was observed, but sex differences in pharmacokinetics is a well-documented phenomenon, both in humans and animals (26). Furthermore, the fetal plasma concentration of $0.1-0.3 \mu \mathrm{M}$ is twice or more than the LOEC of $0.05 \mu \mathrm{M}$ for AR antagonism observed in vitro. Taken together, these data show that an exposure level of $10 \mathrm{mg} / \mathrm{kg}$ bw/day during gestation is appropriate to reach biologically active enzalutamide levels in the fetus and reduce fetal androgen signaling. As a reduced AGD caused by fetal androgen insufficiency is a well-known marker in both humans and rodents, we believe that the observed effects are translatable to humans.

Fetal androgen insufficiency, caused by low androgen levels or blockage of AR signaling, can prevent the male perineum to develop properly and result in a short AGD (8). One previous report shows that enzalutamide induces shortening of male AGD in mice, although they do not state how much shorter AGD is compared to controls (27). We found the average AGD to be $19 \%$ shorter in enzalutamide exposed males than in control males. This effect is less pronounced than previously observed with the prostate cancer drug and AR antagonist flutamide, which shortened male AGD by $19 \%$ at a dose of only $2 \mathrm{mg} / \mathrm{kg}$ (28), and between $35-43 \%$ in the $6-8 \mathrm{mg} / \mathrm{kg}$ dose range $(28,29)$. Conversely, enzalutamide has a greater effect on male AGD than some of the pesticides known to interfere with AR, such as vinclozolin and procymidone, where doses of $50-100 \mathrm{mg} / \mathrm{kg}$ are required to induce a similar shortening of AGD $(28,30-$ 
32). Because of the greater potency and the known mode of action of selective pharmaceuticals like flutamide, finasteride or enzalutamide, they are often better suited as model compounds than less specific environmental chemicals when performing studies aimed at characterizing mechanisms of effects.

Apart from blocking AR action, enzalutamide was also found to disrupt hormone synthesis in the H295R in vitro steroidogenesis assay. Progestagen, androgen and corticosteroid synthesis was downregulated, whereas estrogen synthesis was unaffected. Dehydroepiandrosterone (DHEA), on the other hand, was markedly elevated. It remains unclear exactly how enzalutamide cause these effects in the steroidogenic pathway, but judging from the hormone profile, we speculate that $3 \beta$-hydroxysteroid dehydrogenase is inhibited. With the decrease in androstenedione and testosterone, a decrease in estrogens could have been expected. It is, however, possible that sulfotransferase activity, which is responsible for metabolism of estrogens (33), was reduced. Reduced sulfotransferase activity could equalize the estrogen levels and result in unchanged levels. Another possible explanation could be induction of CYP19 as enzalutamide has previously been shown to induce other CYPs, specifically CYP2C9, CYP2C19 and CYP3A4 (34). These in vitro assays together with physiologically-based kinetic modeling have the potential to be able to predict AGD effects in the future, thereby minimizing animal testing.

Since steroidogenesis was affected in vitro, we also investigated the fetal testis for signs of steroidogenic disruption. We saw increased expression of the key steroidogenic genes Star, Cyp11a1 and Cyp17a1. We initially speculated that this could be a compensatory response to reduced testosterone levels. However, we did not detect any significant reduction in intra-testicular testosterone levels. Thus, at the functional level the effects of enzalutamide on the fetal testis may be diminishable compared to its effect on AR activation in peripheral tissues. In support of this, the in vitro LOEC on testosterone synthesis was $3.1 \mu \mathrm{M}$, a concentration that is much higher than the actual measured fetal levels of $0.1 \mu \mathrm{M}$. Nevertheless, our results point to some degree of disturbance to fetal testis function, but more studies are needed to elucidate the exact mechanism of action of enzalutamide on the steroidogenesis pathway.

\section{Conclusion}

In summary, enzalutamide has strong AR antagonistic effects both in vitro and in vivo. While we observed weak inhibition of steroid synthesis in the rat, this is likely of minor importance in the mode of action, as intra-testicular testosterone levels were not affected. Since enzalutamide is used to treat prostate cancer patients, fetuses will most likely not be exposed to the compound under normal circumstances; albeit, environmental exposure cannot be ruled out. The effects of enzalutamide on the developing male fetus are therefore not of immediate concern, but confirms that enzalutamide is a valuable model compound for future studies on effects of AR antagonists.

\section{Abbreviations}

AGD Anogenital distance 
AR Androgen receptor

GD Gestational day

DHEA Dehydroepiandrosterone

LOEC Lowest Observed Effect Concentration

mCRPC Metastatic Castration-Resistant Prostate Cancer

\section{Declarations}

\section{ACKNOWLEDGEMENTS}

We like to thank our technical staff, Lillian Sztuk, Dorte Lykkegaard Korsbech, Sarah Grundt Simonsen, Birgitte Møller Plesning, Mette Voigt Jessen, and Heidi Letting, for their valuable contributions. We also thank our in-house animal facilities headed by Anne Ørngreen. The Ministry of Environment and Food of Denmark (Food settlement 3 ) is acknowledged for funding.

\section{AUTHORS CONTRIBUTIONS}

CLS, TS and AMV planned the study, all authors contributed some to the design of experiments. CLS, TS, $\mathrm{CT}, \mathrm{MP}, \mathrm{HLF}, \mathrm{KAF}$ and HKLJ, together with support staff, performed the experiments. All authors were involved in the analysis and interpretation of data. CLS drafted the manuscript. All authors helped revise the manuscript and approved the final version.

\section{ADDITIONAL DECLARATIONS}

Ethics Statement: Animal experimentation had ethical approval from the Danish Animal Experiments Inspectorate (license number 2015-15-0201-00553) and was overseen by DTU Food's in-house Animal Welfare committee.

Consent for Publication: Not applicable.

Disclosure Statement: All authors declare that they have no competing interests, neither financial nor nonfinancial, with work presented in this study. 
Data Availability: All data are included in the manuscript. Additional information is available upon request to corresponding author.

Competing financial interests: The authors declare no competing financial interests.

Funding: The work was supported by the Ministry of Environment and Food of Denmark (no grant no.)

\section{References}

1. Wilhelm D, Koopman P. The makings of maleness: towards an integrated view of male sexual development. Nature reviews Genetics. 2006;7(8):620-31. Epub 2006/07/13.

2. Hsieh MH, Breyer BN, Eisenberg ML, Baskin LS. Associations among hypospadias, cryptorchidism, anogenital distance, and endocrine disruption. Current Urology Reports. 2008;9(2):137-42.

3. Thankamony A, Lek N, Carroll D, Williams M, Dunger DB, Acerini CL, et al. Anogenital distance and penile length in infants with hypospadias or cryptorchidism: comparison with normative data. Environmental Health Perspectives. 2014;122(2):207-11.

4. Eisenberg ML, Hsieh MH, Walters RC, Krasnow R, Lipshultz LI. The relationship between anogenital distance, fatherhood, and fertility in adult men. PloS one. 2011;6(5):e18973. Epub 2011/05/19.

5. Mendiola J, Stahlhut RW, Jorgensen N, Liu F, Swan SH. Shorter anogenital distance predicts poorer semen quality in young men in Rochester, New York. Environmental health perspectives. 2011;119(7):958-63. Epub 2011/03/08.

6. Christiansen S, Scholze M, Axelstad M, Boberg J, Kortenkamp A, Hass U. Combined exposure to antiandrogens causes markedly increased frequencies of hypospadias in the rat. International journal of andrology. 2008;31(2):241-8. Epub 2008/03/05.

7. Dean A, Sharpe RM. Clinical review: Anogenital distance or digit length ratio as measures of fetal androgen exposure: relationship to male reproductive development and its disorders. The Journal of clinical endocrinology and metabolism. 2013;98(6):2230-8. Epub 2013/04/10.

8. Schwartz CL, Christiansen S, Vinggaard AM, Axelstad M, Hass U, Svingen T. Anogenital distance as a toxicological or clinical marker for fetal androgen action and risk for reproductive disorders. Arch Toxicol. 2019;93:253-72. Epub 14 November 2018.

9. OECD. Test No. 443: Extended One-Generation Reproductive Toxicity Study, OECD Guidelines for the Testing of Chemicals, Section 4. Paris: OECD Publishing, 2018.

10. OECD. Test No. 421: Reproduction/Developmental Toxicity Screening Test, OECD Guidelines for the Testing of Chemicals, Section 4. Paris: OECD Publishing, 2016.

11. OECD. Test No. 422: Combined Repeated Dose Toxicity Study with the Reproduction/Developmental Toxicity Screening Test, OECD Guidelines for the Testing of Chemicals, Section 4. Paris: OECD Publishing, 2016. 
12. OECD. Test No. 414: Prenatal Development Toxicity Study, OECD Guidelines for the Testing of Chemicals, Section 4. Paris: OECD Publishing, 2018.

13. Schalken J, Fitzpatrick JM. Enzalutamide: targeting the androgen signalling pathway in metastatic castration-resistant prostate cancer. BJU international. 2016;117(2):215-25. Epub 2015/03/31.

14. Tran C, Ouk S, Clegg NJ, Chen Y, Watson PA, Arora V, et al. Development of a second-generation antiandrogen for treatment of advanced prostate cancer. Science. 2009;324(5928):787-90. Epub 2009/04/11.

15. Chen CD, Welsbie DS, Tran C, Baek SH, Chen R, Vessella R, et al. Molecular determinants of resistance to antiandrogen therapy. Nature medicine. 2004;10(1):33-9. Epub 2004/01/02.

16. Masiello D, Cheng S, Bubley GJ, Lu ML, Balk SP. Bicalutamide functions as an androgen receptor antagonist by assembly of a transcriptionally inactive receptor. The Journal of biological chemistry. 2002;277(29):26321-6. Epub 2002/05/17.

17. Baek SH, Ohgi KA, Nelson CA, Welsbie D, Chen C, Sawyers CL, et al. Ligand-specific allosteric regulation of coactivator functions of androgen receptor in prostate cancer cells. Proceedings of the National Academy of Sciences of the United States of America. 2006;103(9):3100-5. Epub 2006/02/24.

18. Schwartz CL, Vinggaard AM, Christiansen S, Darde TA, Chalmel F, Svingen T. Distinct transcriptional profiles of the female, male and finasteride-induced feminized male anogenital region in rat fetuses. Toxicological Sciences. 2019;Accepted, February 3rd, 2019.

19. OECD. Test No. 458: Stably Transfected Human Androgen Receptor Transcriptional Activation Assay for Detection of Androgenic Agonist and Antagonist Activity of Chemicals. OECD Guidelines for the Testing of Chemicals, Section 4 Paris: OECD Publishing, 2016.

20. OECD. Test No. 456: H295R Steroidogenesis Assay, OECD Guidelines for the Testing of Chemicals, Section 4. Paris: OECD Publishing, 2011.

21. Mortensen SK, Pedersen M. Confirmatory analysis of acetylgestagens in plasma using liquid chromatography-tandem mass spectrometry. Analytica chimica acta. 2007;586(1-2):217-22. Epub 2007/03/28.

22. Rosenmai AK, Nielsen FK, Pedersen M, Hadrup N, Trier X, Christensen JH, et al. Fluorochemicals used in food packaging inhibit male sex hormone synthesis. Toxicology and applied pharmacology. 2013;266(1):132-42. Epub 2012/11/13.

23. Svingen T, Letting H, Hadrup N, Hass U, Vinggaard AM. Selection of reference genes for quantitative RT-PCR (RT-qPCR) analysis of rat tissues under physiological and toxicological conditions. PeerJ. 2015;3:e855. Epub 2015/04/01.

24. Laier P, Metzdorff SB, Borch J, Hagen ML, Hass U, Christiansen S, et al. Mechanisms of action underlying the antiandrogenic effects of the fungicide prochloraz. Toxicology and applied pharmacology. 2006;213(2):160-71. Epub 2005/12/27. 
25. FDA. https://www.accessdata.fda.gov/drugsatfda_docs/nda/2012/2034150rig1s000PharmR.pdf. San Francisco, CA94105: Center for Drug Evaluation and Research, 2012 May, 2010. Report No.: Contract No.: 203415.

26. Morris ME, Lee HJ, Predko LM. Gender differences in the membrane transport of endogenous and exogenous compounds. Pharmacological reviews. 2003;55(2):229-40. Epub 2003/05/30.

27. TGA. Australian Public Assessment Report for Enzalutamide. Australia: Therapeutic Goods Administration, 2014.

28. Hass U, Scholze M, Christiansen S, Dalgaard M, Vinggaard AM, Axelstad M, et al. Combined exposure to anti-androgens exacerbates disruption of sexual differentiation in the rat. Environmental health perspectives. 2007;115 Suppl 1:122-8. Epub 2008/01/05.

29. Mclntyre BS, Barlow NJ, Foster PM. Androgen-mediated development in male rat offspring exposed to flutamide in utero: permanence and correlation of early postnatal changes in anogenital distance and nipple retention with malformations in androgen-dependent tissues. Toxicological sciences : an official journal of the Society of Toxicology. 2001;62(2):236-49. Epub 2001/07/14.

30. Matsuura I, Saitoh T, Ashina M, Wako Y, Iwata H, Toyota N, et al. Evaluation of a two-generation reproduction toxicity study adding endpoints to detect endocrine disrupting activity using vinclozolin. The Journal of toxicological sciences. 2005;30 Spec No.:163-88. Epub 2006/04/28.

31. Schneider S, Kaufmann W, Strauss V, van Ravenzwaay B. Vinclozolin: a feasibility and sensitivity study of the ILSI-HESI F1-extended one-generation rat reproduction protocol. Regulatory toxicology and pharmacology : RTP. 2011;59(1):91-100. Epub 2010/09/30.

32. Wolf C, Jr., Lambright C, Mann P, Price M, Cooper RL, Ostby J, et al. Administration of potentially antiandrogenic pesticides (procymidone, linuron, iprodione, chlozolinate, p,p'-DDE, and ketoconazole) and toxic substances (dibutyl- and diethylhexyl phthalate, PCB 169, and ethane dimethane sulphonate) during sexual differentiation produces diverse profiles of reproductive malformations in the male rat. Toxicology and industrial health. 1999;15(1-2):94-118. Epub 1999/04/03.

33. Raftogianis R, Creveling C, Weinshilboum R, Weisz J. Chapter 6: Estrogen Metabolism by Conjugation. JNCl Monographs. 2000;2000(27):113-24.

34. Gibbons JA, de Vries M, Krauwinkel W, Ohtsu Y, Noukens J, van der Walt JS, et al. Pharmacokinetic Drug Interaction Studies with Enzalutamide. Clinical pharmacokinetics. 2015;54(10):1057-69. Epub 2015/05/02.

\section{Tables}




\section{Table 1 - Pregnancy and litter data}

Data represent group means, based on litter means \pm SD after oral exposure GD7-21.

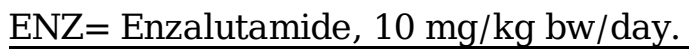

\begin{tabular}{lll}
\hline GD21 Caesarean section & Control & ENZ \\
\hline No. of litters & $\mathrm{N}=6$ & $\mathrm{~N}=6$ \\
\hline Maternal body weight $(\mathrm{g}), \mathrm{GD} 7$ & $262.2 \pm 12.2$ & $269.2 \pm 11.4$ \\
\hline No. of fetuses & $14.0 \pm 2.4$ & $13.2 \pm 2.3$ \\
\hline Maternal bw gain GD7- 21 $(\mathrm{g})$ & $115.3 \pm 18.8$ & $124.5 \pm 17.0$ \\
\hline Adjusted maternal bw $(\mathrm{g})^{\wedge}$ & $289.7 \pm 20.0$ & $307.8 \pm 18.7$ \\
\hline Uterus weight $(\mathrm{g})$ & $87.8 \pm 10.8$ & $85.9 \pm 13.8$ \\
\hline Fetal weight male $(\mathrm{g})(\mathrm{bw})$ & $4.3 \pm 0.4$ & $4.3 \pm 0.2$ \\
\hline Fetal weight female $(\mathrm{g})(\mathrm{bw})$ & $4.2 \pm 0.3$ & $4.0 \pm 0.3$ \\
\hline Male AGD $(\mathrm{mm})$ & $3.64 \pm 0.2$ & $2.96 \pm 0.1^{* *}$ \\
\hline Male AGD index & $2.24 \pm 0.03$ & $1.82 \pm 0.07^{* *}$ \\
\hline Female AGD $(\mathrm{mm})$ & $1.81 \pm 0.09$ & $1.67 \pm 0.08$ \\
\hline Female AGD index & $1.13 \pm 0.04$ & $1.06 \pm 0.07$ \\
\hline AGD index AGD & &
\end{tabular}

AGD index $=$ AGD divided by cube root of the bodyweight 
A

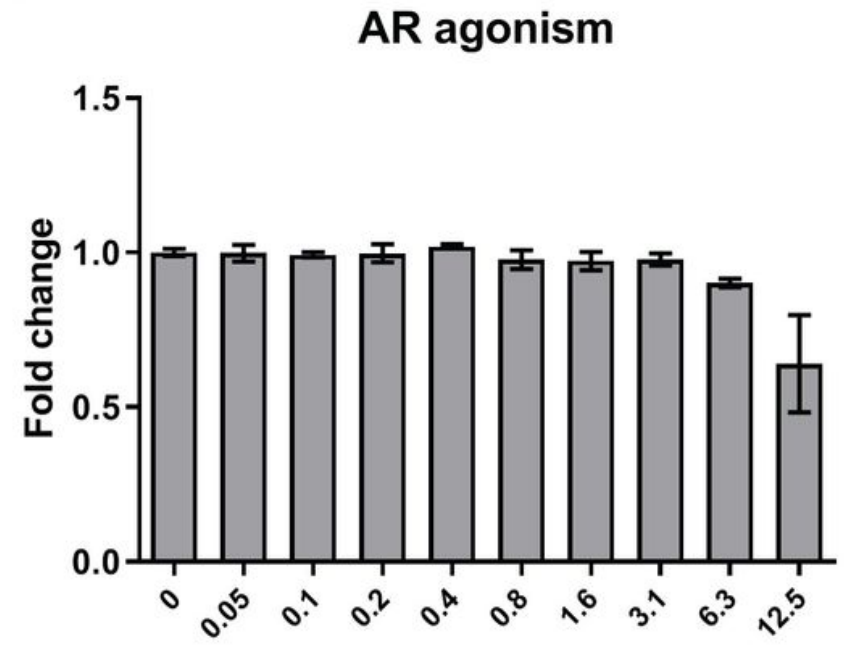

Enzalutamide $[\mu \mathrm{M}]$
B

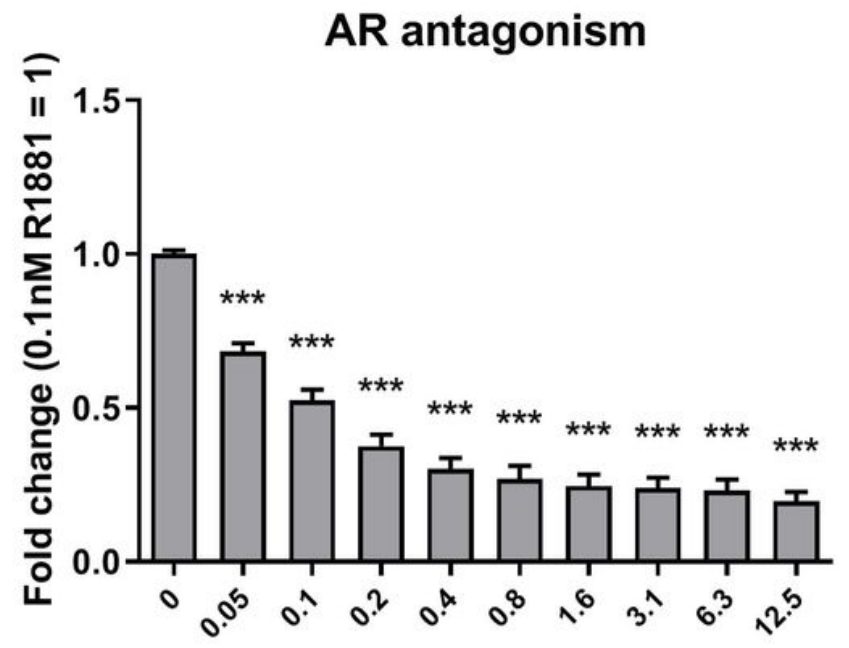

Enzalutamide $[\mu \mathrm{M}]$

C

Cytotoxicity

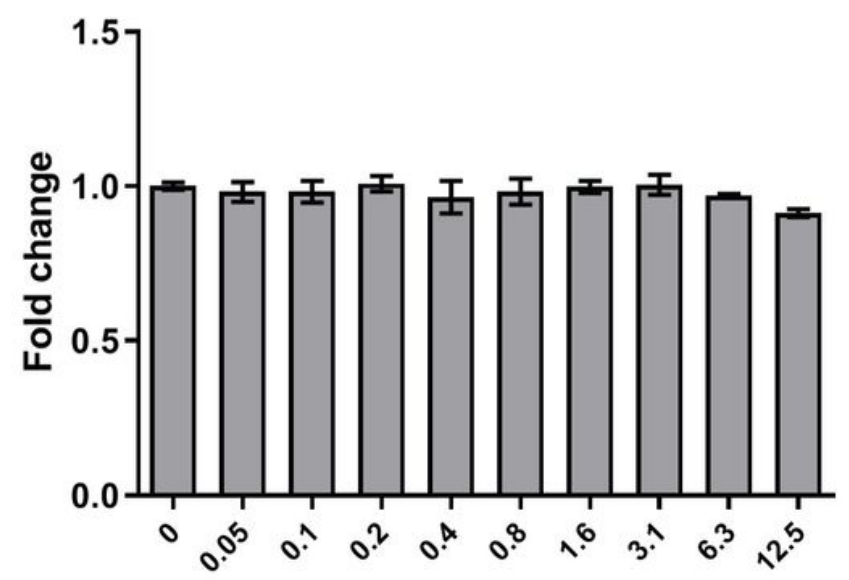

Enzalutamide $[\mu \mathrm{M}]$

Figure 1

Enzalutamide acts as an AR antagonist: Dose-response curves for enzalutamide in the AR-EcoScreenTM. A: Cells were incubated with increasing concentrations of enzalutamide $(\mu \mathrm{M})$. The values are mean $\pm S E M$ $(n=3)$ and are presented as fold change in firefly luminescence. B: Cells were incubated with increasing concentrations of enzalutamide $(\mu M)$ in the presence of $0.1 \mathrm{nM}$ R1881. The values are mean $\pm S E M(n=3)$ and are presented as fold change in firefly luminescence relative to the response achieved with $0.1 \mathrm{nM}$ R1881, which is set to 1 . $* \star \star$ : Significantly different from control, $p<0.001$. C: Induction of cytotoxicity following enzalutamide exposure. The values are mean $\pm \operatorname{SEM}(n=3)$ and are presented as fold change in Renilla luminescence. 
Cholesterol

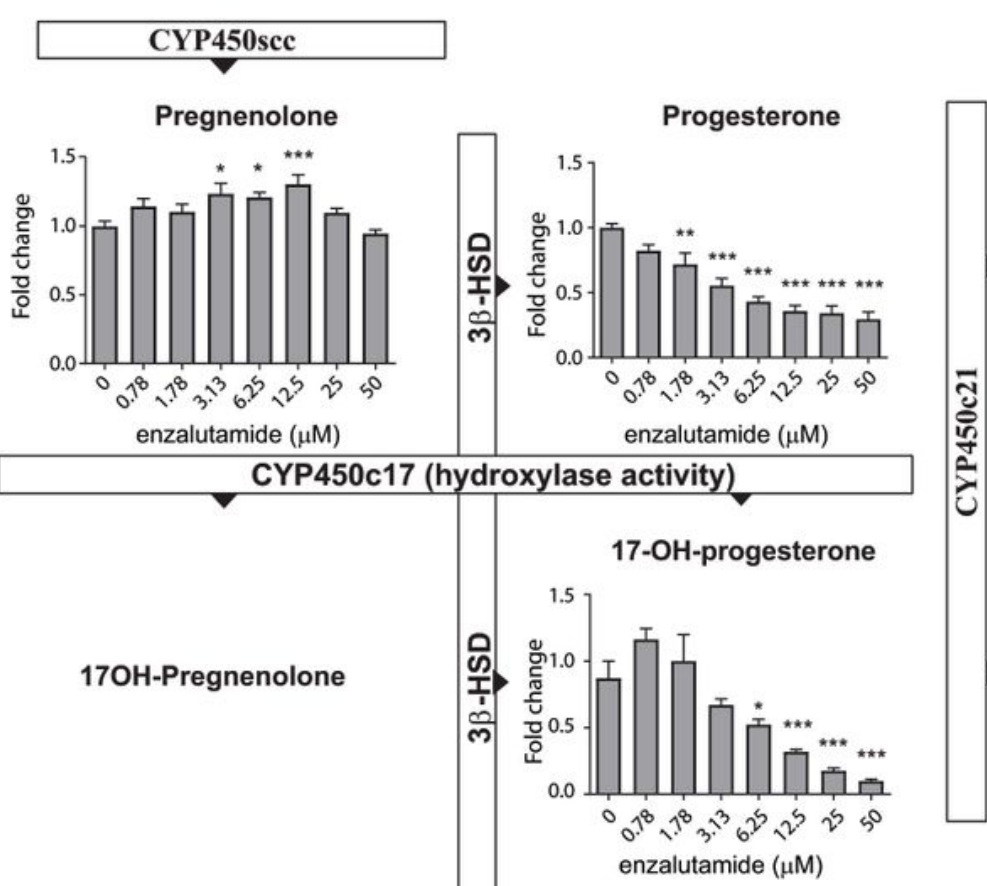

Aldosterone

Aldosterone synthas
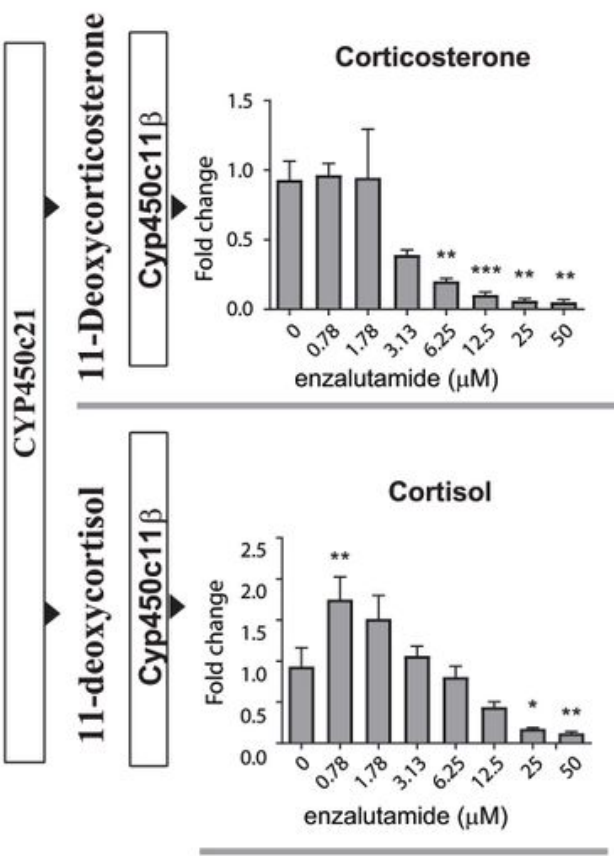

Estrone

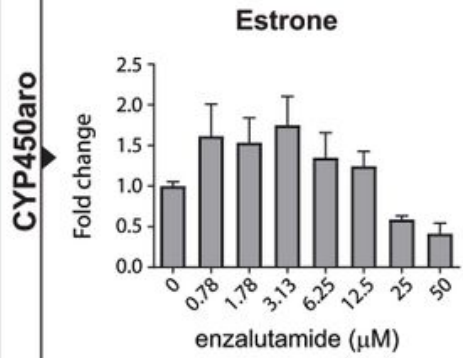

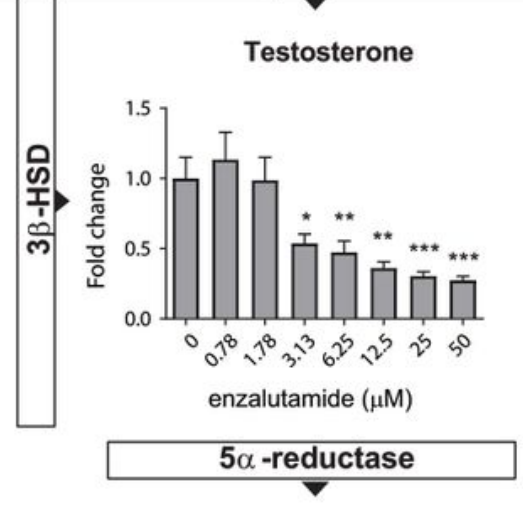

Estradiol

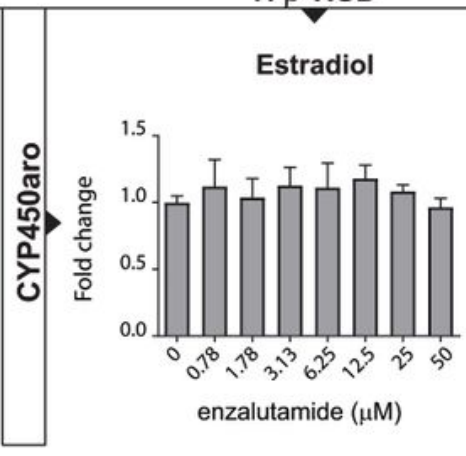

Dihydrotestosterone

\section{Figure 2}

Enzalutamide affects steroidogenesis: Relative levels of produced steroid hormones by H295R (CRL$2128 \mathrm{TM})$ cells exposed to increasing concentrations of enzalutamide $(\mu \mathrm{M})$ for 48 hours. Results shown are mean \pm SEM ( $n=3$ and $n=2$ for DHEA). *: Significantly different from control, $p<0.05$. **: Significantly different from control, $p<0.01$. ***: Significantly different from control, $p<0.001$. 


\section{Enzalutamide at GD21}

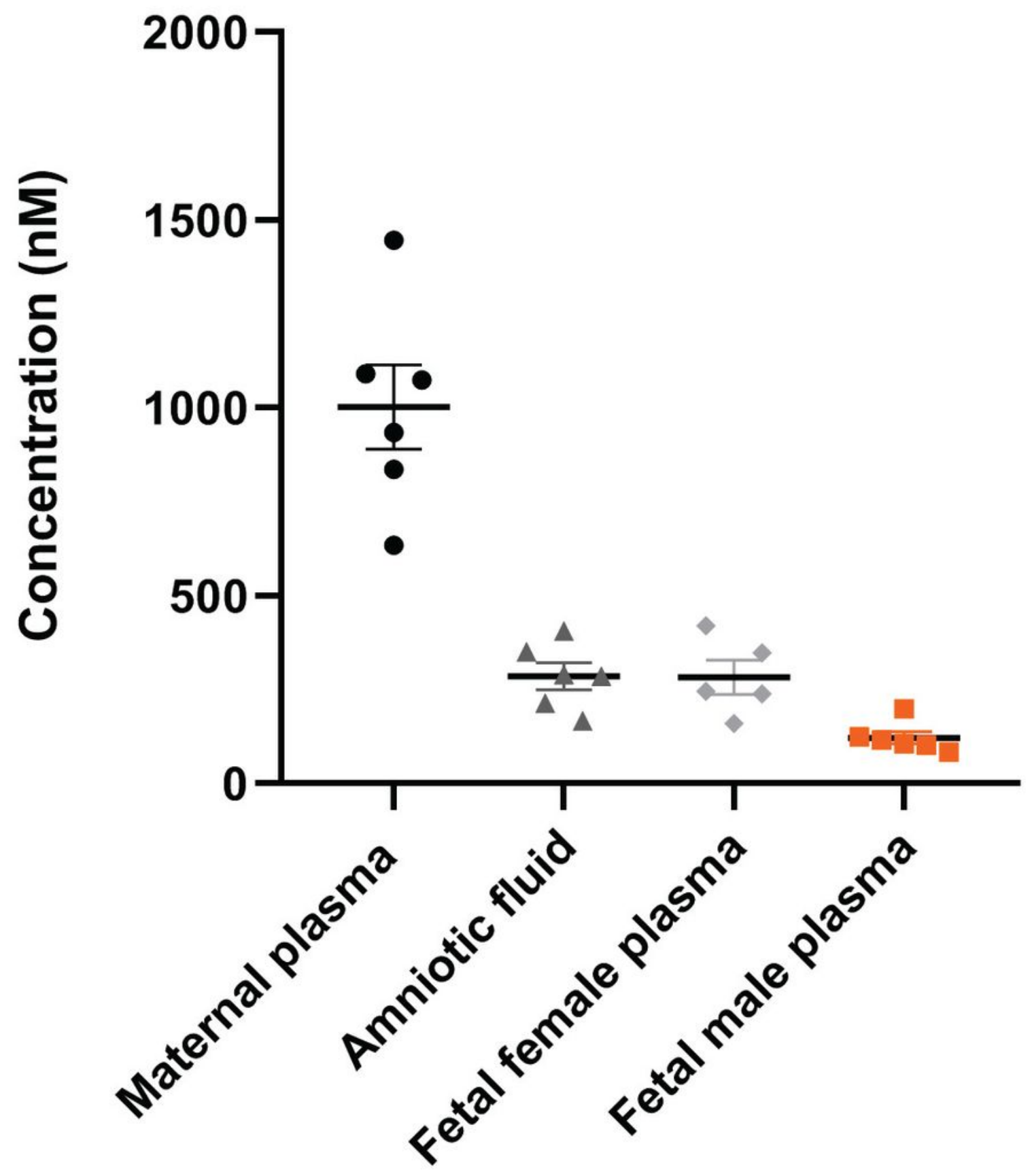

Figure 3

Enzalutamide levels in plasma and amniotic fluid: Concentration (nM) of enzalutamide in maternal plasma, amniotic fluid or plasma of the male and female fetuses at GD21 following exposure of pregnant rats from GD7 to GD21 to $10 \mathrm{mg} / \mathrm{kg}$ bw/day of enzalutamide. Results shown are mean \pm SEM of pooled samples from 6 litters. 


\section{Male Anogenital Distance index}

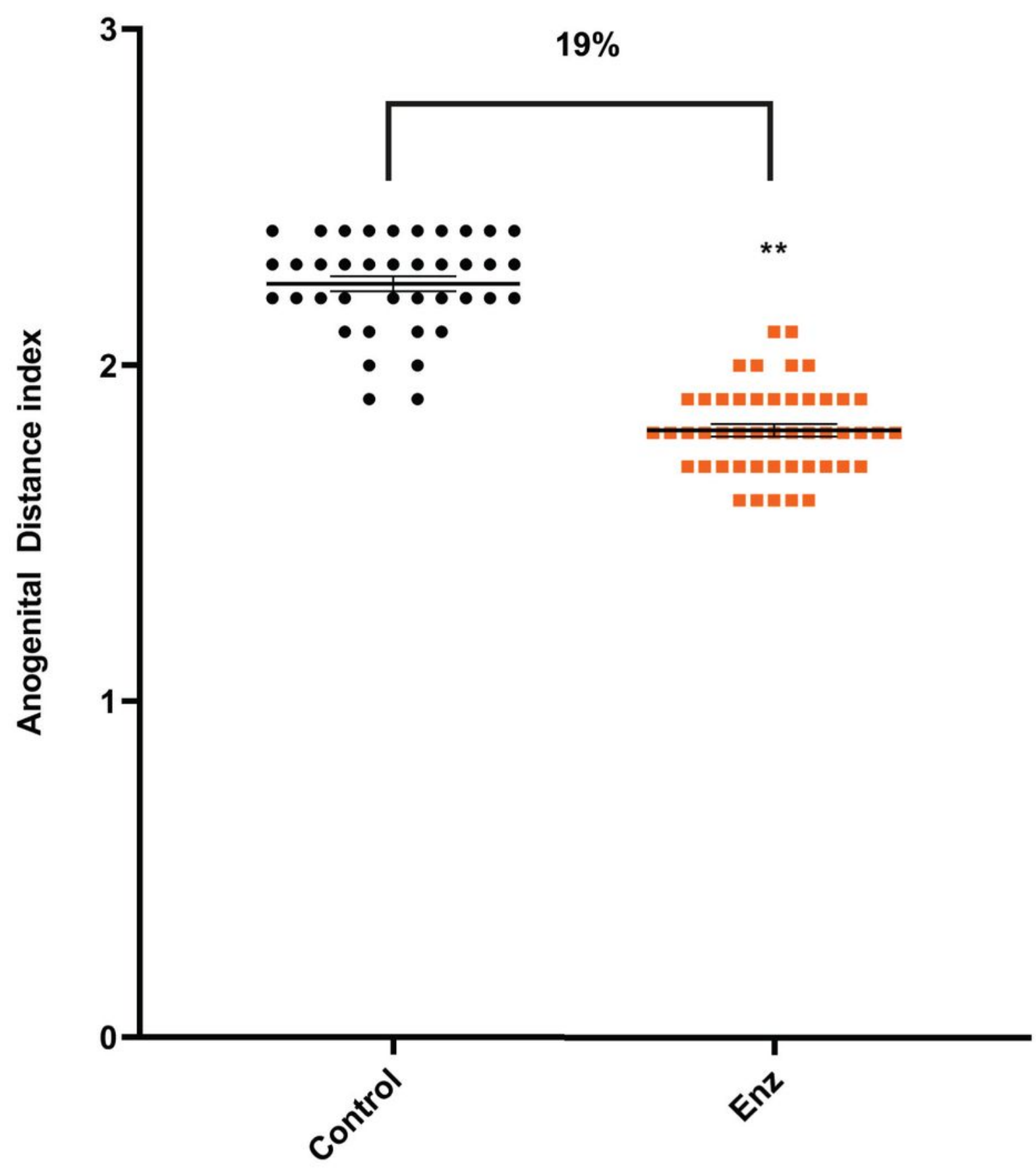

Figure 4

Enzalutamide reduces the male anogenital distance index: Anogenital distance index (AGD/cube root of bw) of control males (Control) and enzalutamide exposed males (enzalutamide, $10 \mathrm{mg} / \mathrm{kg} \mathrm{bw} /$ day GD7GD21). Results are shown as mean $\pm S E M, n=6$ litters/group, with each dot representing one male fetus. **: Significantly different from control, $p<0.01$ (with bw as covariate). 

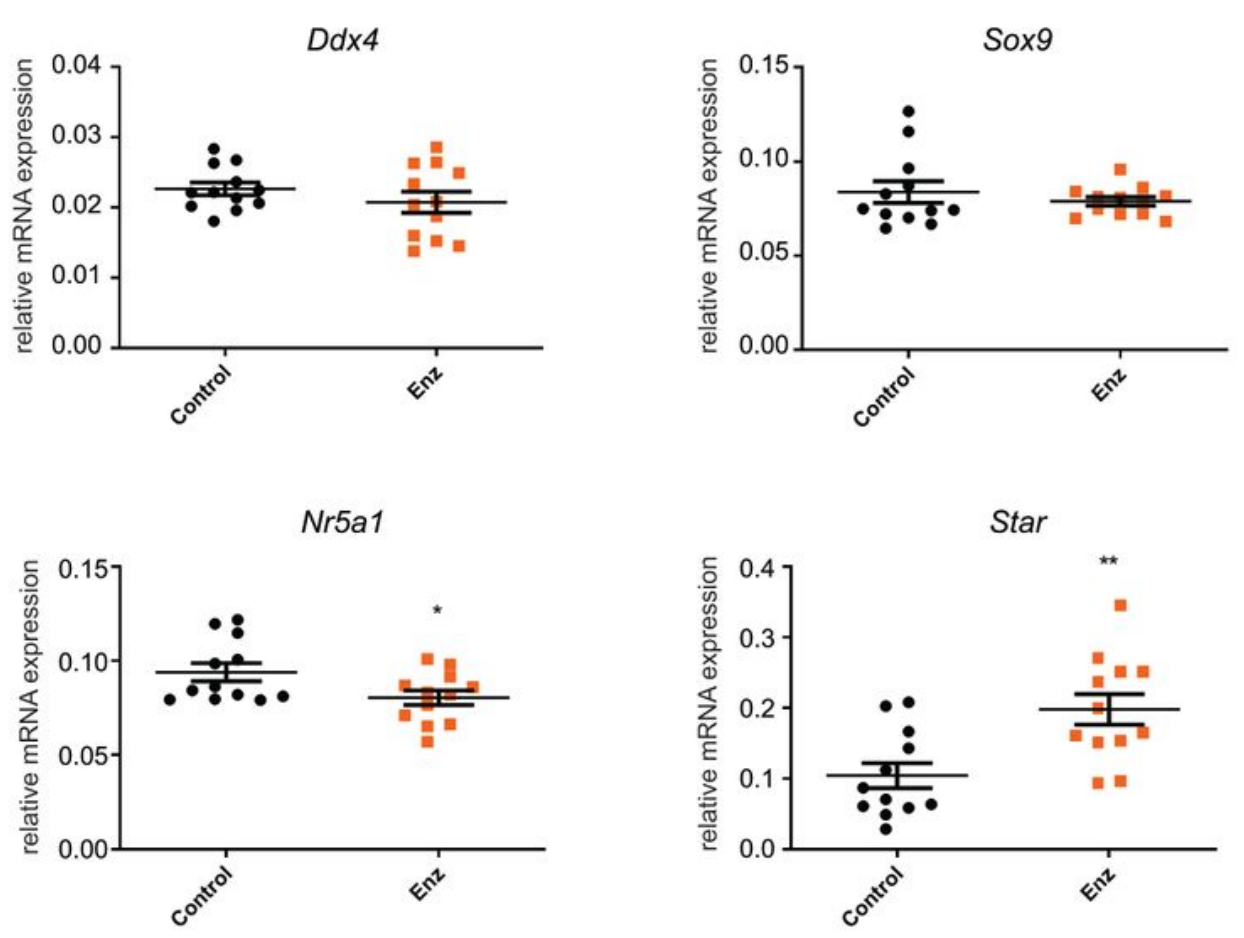

Cyp11a1

Cyp17a1
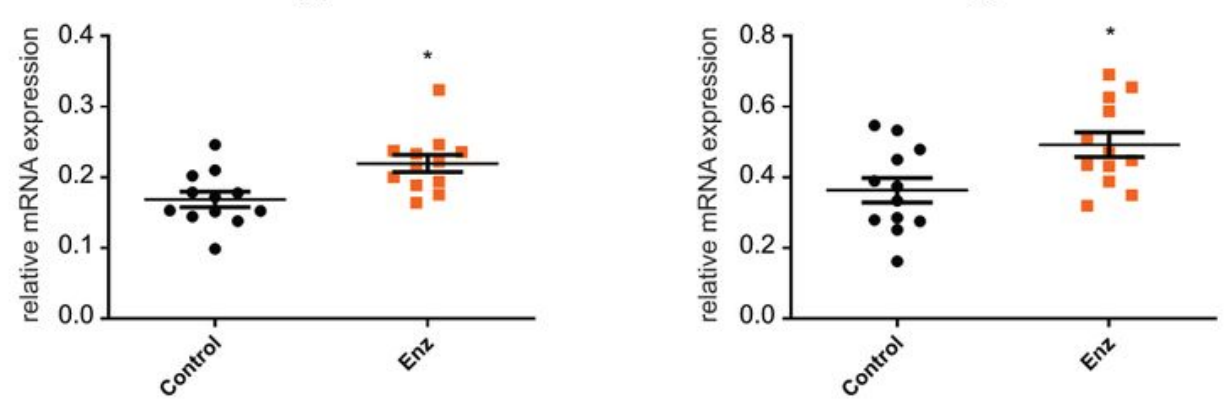

Hsd3b1

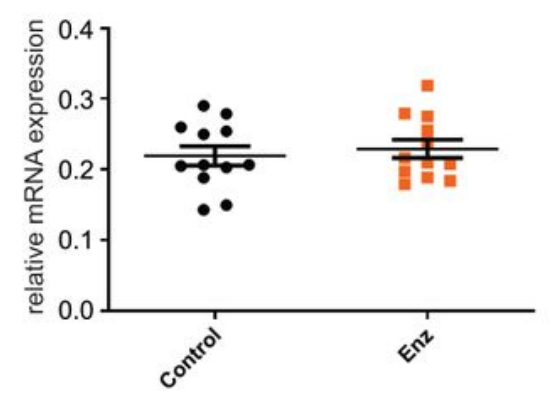

Hsd17b1

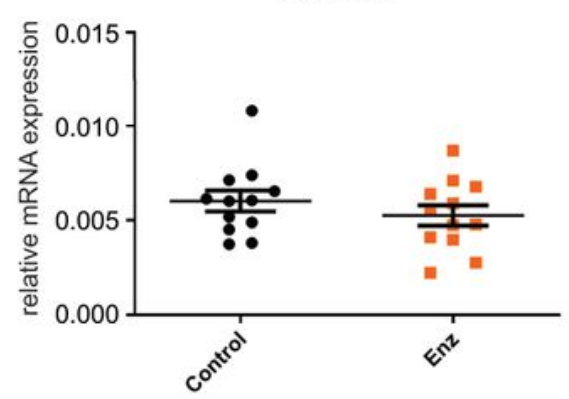

\section{Figure 5}

Enzalutamide affects gene expression of steroidogenic enzymes: RT-qPCR of steroidogenic enzymes. Results are 2- $\triangle C$ CT values shown as mean $\pm S E M(n=12 /$ group). Enz: Exposed to enzalutamide, $10 \mathrm{mg} / \mathrm{kg}$ bw/day GD7-GD21. *: Significantly different from control, $p<0.05$. **: Significantly different from control males, $\mathrm{p}<0.01$. 


\section{Intratesticular testosterone}

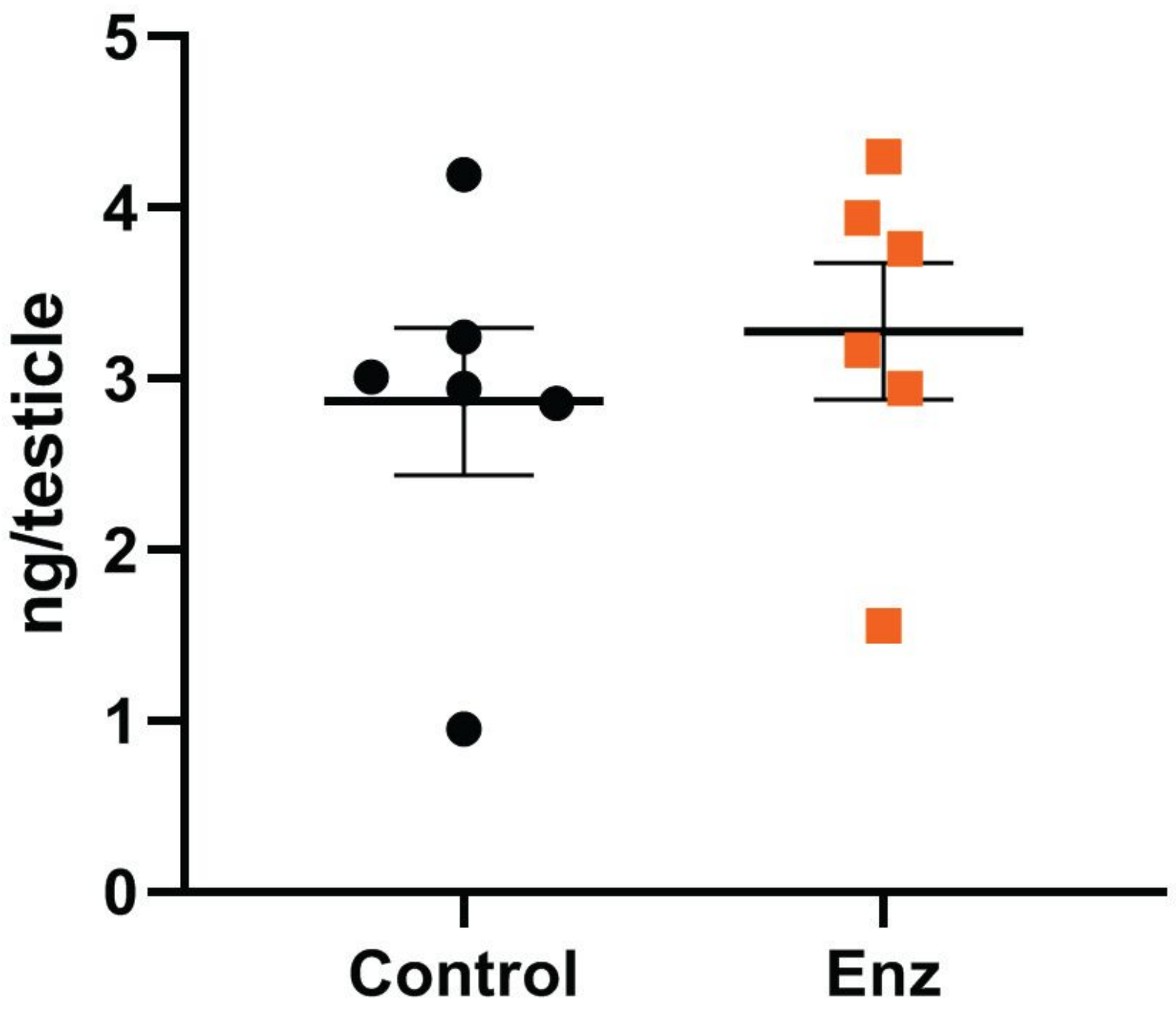

Figure 6

Enzalutamide does not affect intra-testicular testosterone at GD 21: Intra-testicular testosterone concentration at GD21 (ng testosterone/testicle) following exposure to $10 \mathrm{mg} / \mathrm{kg} \mathrm{bw} /$ day of enzalutamide (Enz) from GD7 to GD21. Results shown are mean \pm SEM of 1 testicle from 6 fetuses/group. 


\section{Ctrl}
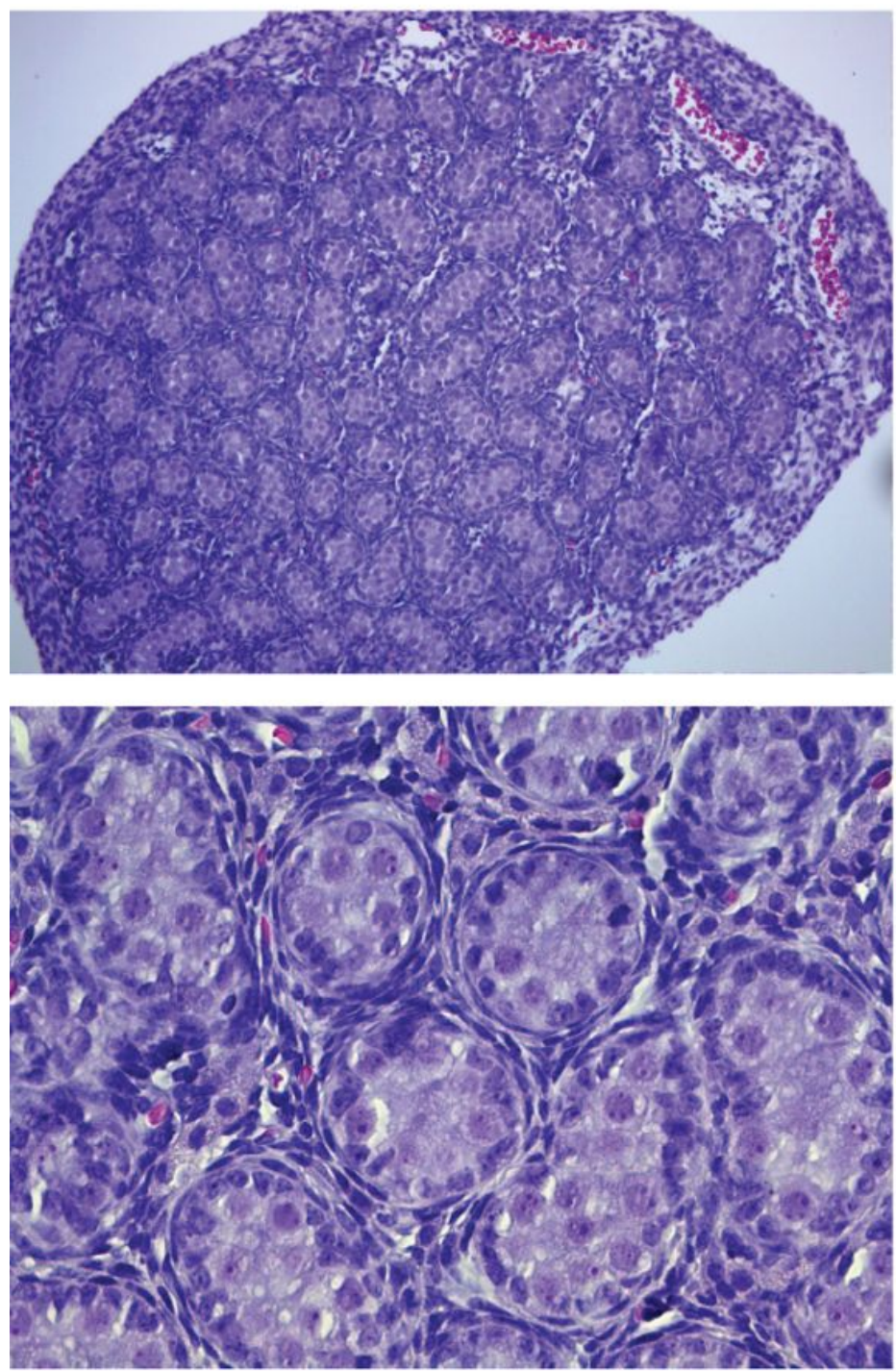

\section{Enz}
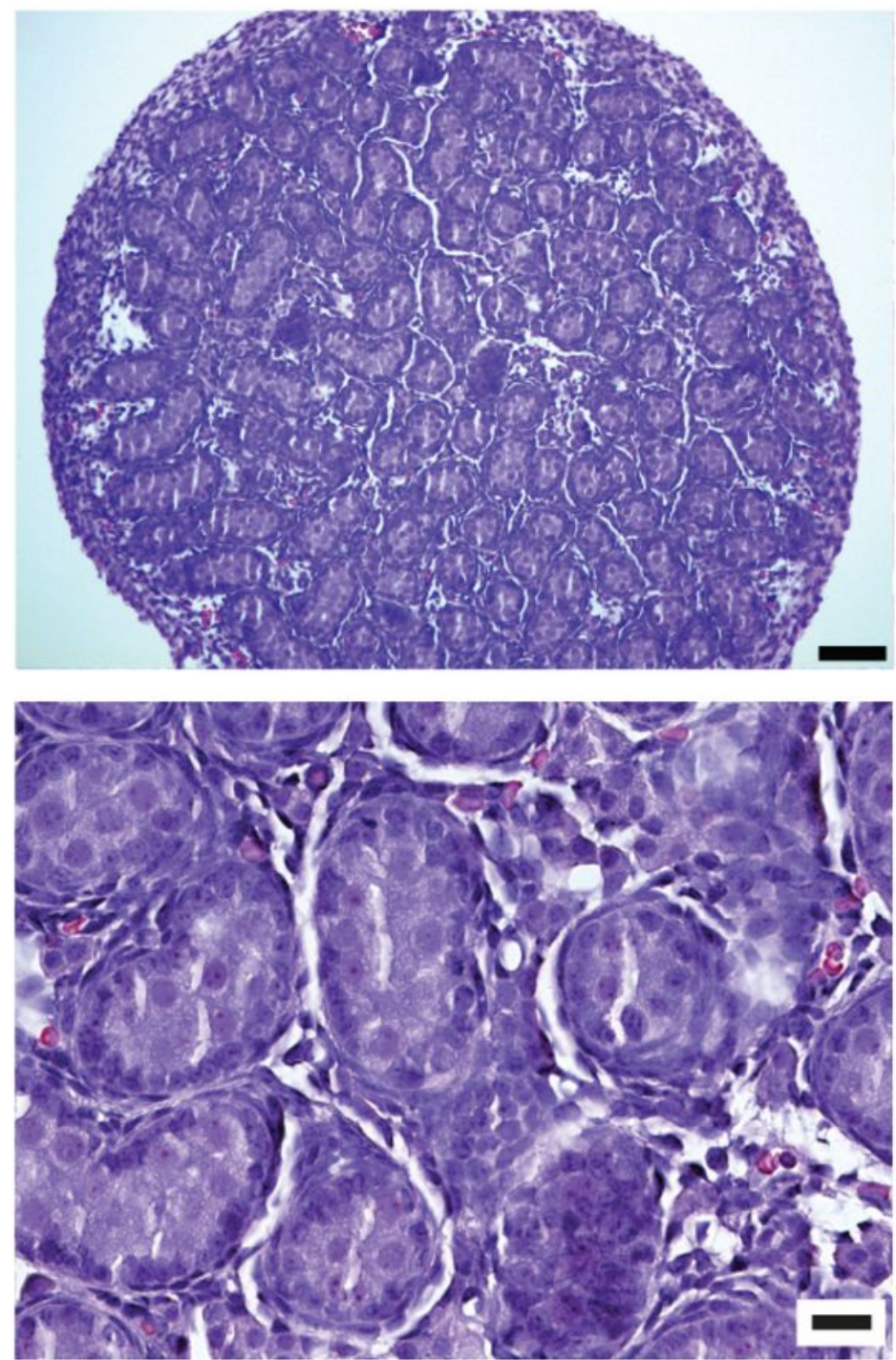

\section{Figure 7}

Enzalutamide does not affect fetal testis histology: Cross-sections of formalin-fixed GD21 testes from controls or enzalutamide exposed males $(10 \mathrm{mg} / \mathrm{kg}$ bw/day, GD7-21) were stained with hematoxylin \& eosin (H\&E). $(n=3)$; scale bar upper panel $=100 \mu \mathrm{m}$, lower panel $=20 \mu \mathrm{m}$. 